Syntax Literate: Jurnal Ilmiah Indonesia p-ISSN: 2541-0849

e-ISSN: 2548-1398

Vol. 6, No. 1, Januari 2021

\title{
PENGARUH EXPERIENTIAL MARKETING DAN KUALITAS PELAYANAN TERHADAP KEPUASAN KONSUMEN DAN WORD OF MOUTH
}

\section{Heryanto, Tetra Hidayati dan Sri Wahyuni}

Fakultas Ekonomi dan Bisnis, Universitas Mulawarman, Indonesia

Email: heryanto.gina@gmail.com, tetra.hidayati@feb.unmul.ac.id dan sriwahyuni.unmul@gmail.com

\begin{abstract}
The purpose of this study was to analyze the effect of experiential marketing on customer satisfaction, to analyze the effect of service quality on customer satisfaction, to analyze the effect of customer satisfaction on word of mouth, to analyze the effect of experiential marketing on word of mouth through customer satisfaction, and to analyze the effect of quality of service to word of mouth through customer satisfaction. This type of research uses survey research with a causative approach. The population in this study were consumers at the Soto Banjar Asli Ayam Kampung Restaurant in Targhibul Ikhwan in Samarinda. The data analysis used is covariance-based SEM. The results of this study show that experiential marketing has a positive and insignificant effect on customer satisfaction, service quality has a positive and significant effect on customer satisfaction, customer satisfaction has a positive and significant effect on word of mouth, experiential marketing has a positive and insignificant effect on word of mouth through customer satisfaction, and service quality positive and significant effect on word of mouth through customer satisfaction.
\end{abstract}

Keywords: Experiential Marketing, Services Quality, Consumen Satisfaction, and Word of Mouth.

\footnotetext{
Abstrak

Tujuan dalam penelitian ini adalah untuk menganalisis pengaruh experiential marketing terhadap kepuasan konsumen, untuk menganalisis pengaruh kualitas pelayanan terhadap kepuasan konsumen, untuk menganalisis pengaruh kepuasan konsumen terhadap word of mouth, untuk menganalisis pengaruh experiential marketing terhadap word of mouth melalui kepuasan konsumen, dan untuk menganalisis pengaruh kualitas pelayanan terhadap word of mouth melalui kepuasan konsumen. Jenis penelitian ini menggunakan penelitian survei dengan pendekatan kausatif. Populasi dalam penelitian ini adalah konsumen pada Rumah Makan Soto Banjar Asli Ayam Kampung Targhibul Ikhwan di Samarinda. Analisa data yang digunakan adalah SEM berbasis covariance. Hasil penelitian ini menunjukkan bahwa experiential marketing berpengaruh positif dan tidak signifikan terhadap kepuasan konsumen, kualitas pelayanan berpengaruh positif dan signifikan terhadap kepuasan konsumen, kepuasan konsumen berpengaruh positif dan signifikan terhadap word of mouth, experiential marketing berpengruh positif dan tidak signifikan terhadap word of mouth melalui kepuasan konsumen, dan kualitas
} 
Heryanto, Tetra Hidayani dan Sri Wahyuni

pelayanan berpengaruh positif dan signifikan terhadap word of mouth melalui kepuasan konsumen.

Kata Kunci: Experiential Marketing, Kualitas Pelayanan, Kepuasan Konsumen, dan Word of Mouth.

Coresponden Author

Email: heryanto.gina@gmail.com

Artikel dengan akses terbuka dibawah lisensi

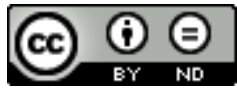

\section{Pendahuluan}

Experiential marketing merupakan sebuah konsep pemasaran yang digunakan oleh pemasar untuk mengemas produk atau jasa sehingga mampu menawarkan pengalaman emosi hingga menyentuh hati dan perasaan konsumen. Konsep pemasaran ini dapat mempengaruhi rasa senang atau puas konsumen atau pelanggan ketika mengkonsumsi kuliner Soto Banjar Asli Ayam Kampung pada Targhibul Ikhwan di Samarinda. Experiential Marketing sangat berperan penting dalam menciptakan kepuasan konsumen karena pelayanan yang diberikan oleh penyedia jasa serta fasilitas yang disediakan, dan berbagai faktor lain dapat mempengaruhi emosional pelanggan yang secara langsung dapat berpengaruh terhadap puas atau tidaknya konsumen.

Hal ini sesuai dengan penelitian yang dilakukan oleh (Muhammad \& Artanti, 2016) membuktikan bahwa experiential marketing secara langsung berpengaruh positif dan signfikan terhadap kepuasan konsumen. Namun, penelitian berbeda dilakukan oleh (Aristiawan, et. al. 2019) membuktikan bahwa experiential marketing berpengaruh positif dan tidak signifikan terhadap kepuasan konsumen. Sedangkan penelitian lainnya memperkuat bahwa (Lin, 2019) membuktikan bahwa experiential marketing berpengaruh positif terhadap customer satisfaction.

Tingkat kepuasan individu konsumen merupakan perbedaan antara kinerja dengan harapan. Tingkat kepuasan konsumen merupakan aspek yang perlu diperhatikan oleh pemilik usaha pada Soto Banjar Asli Ayam Kampung Targhibul Ikhwan di Samarinda ini yang mana dengan konsumen merasa puas khususnya pada kualitas jasa atau pelayanan maka besar kemungkinan konsumen akan merekomendasikan kepada orang lain seperti teman atau keluarga dan mengakibatkan terjadinya pembelian yang berulang. Kepuasan konsumen tercipta apabila kualitas pelayanan yang diberikan oleh pemilik usaha di tempat ini sesuai dengan kebutuhan atau harapan karena baik atau buruknya kualitas tergantung pada kemampuan penyedia jasa dalam memenuhi harapan konsumen. Jika kualitas pelayanan yang diberikan oleh penyedia jasa tidak baik maka secara langsung dapat berdampak pada tingkat kepuasan konsumen yang semakin menurun dan sebaliknya.

Hal ini sesuai dengan penelitian yang dilakukan oleh (Perdana dan Soesanto, 2015) membuktikan bahwa kualitas pelayanan berpengarauh positif dan signifikan terhadap kepuasan pelanggan. Namun, penelitian berbeda dilakukan oleh (Kurniawan, 
2016) membuktikan bahwa kualitas pelayanan berpengaruh negatif dan tidak signifikan terhadap kepuasan. Sedangkan penelitian lainnya dari (Indriani, et. al. 2019) menguatkan bahwa secara langsung kualitas pelayanan berpengaruh terhadap kepuasan konsumen.

Kepuasan konsumen merupakan hal yang penting bagi penyedia jasa karena konsumen atau pelanggan akan menyebarkan rasa puasnya ke calon pelanggan atau orang lainnya sehingga akan menaikkan citra perusahaan. Jika konsumen atau pelanggan merasa puas akan kualitas pelayanan yang diberikan oleh penyedia jasa maka secara tidak langsung dapat menciptakan word of mouth (WOM) kepada rekan atau keluarganya.

Hal ini juga sejalan dengan penelitian yang telah dilakukan membuktikan bahwa secara tidak langsung kualitas pelayanan berpengaruh positif dan signifikan terhadap word of mouth melalui kepuasan konsumen. Namun, penelitian berbeda dilakukan oleh (Indriani, et. al. 2019) yang membuktikan bahwa secara tidak langsung kualitas pelayanan tidak berpengaruh signifikan terhadap word of mouth melalui kepuasan konsumen. Kemudian penelitian lainnya dari (Wahyu \& Gorda, 2017) membuktikan bahwa bahwa secara tidak langsung kualitas pelayanan berpengaruh positif dan signifikan terhadap word of mouth melalui kepuasan konsumen.

\section{Metode Penelitian}

Jenis penelitian ini menggunakan penelitian survei dengan pendekatan kausatif. Populasi dalam penelitian ini adalah konsumen pada Rumah Makan Soto Banjar Asli Ayam Kampung Targhibul Ikhwan di Samarinda. Populasi merupakan wilayah generalisasi yang terdiri atas objek maupun subjek yang memiliki karakteristik tertentu yang telah ditetapkan oleh peniliti. Populasi dalam penelitian ini adalah seluruh konsumen pada Rumah Makan Soto Banjar Asli Ayam Kampung Targhibul Ikhwan di Samarinda dengan sampel yang ditentukan yakni sebesar 180 responden, Menurut (Collier, 2020) mengemukakan bahwa structural equation modelling (SEM) adalah metode statistik yang meneliti hubungan antara banyak variabel secara simultan. SEM tidak dianggap sebagai prosedur tunggal melainkan keluarga teknik statistik terkait. Kelompok teknik analisis ini meneliti sifat pengukuran variabel bersama dengan keterkaitan antar variabel dan sering dilihat sebagai kombinasi regresi dan analisis faktor.

\section{Hasil dan Pembahasan}

\section{A. Analisis SEM}

1. Memilih Matriks Input dan Teknik Estimasi

Teknik estimasi yang akan digunakan adalah maximum likehood estimation (MLE) yang akan dilakukan secara bertahap yakni estimasi measurement model dengan teknik confirmatory factor analysis dan structural equation model melalui analisis full model. Berikut diagram full model seperti pada Gambar 2 dibawah ini. 


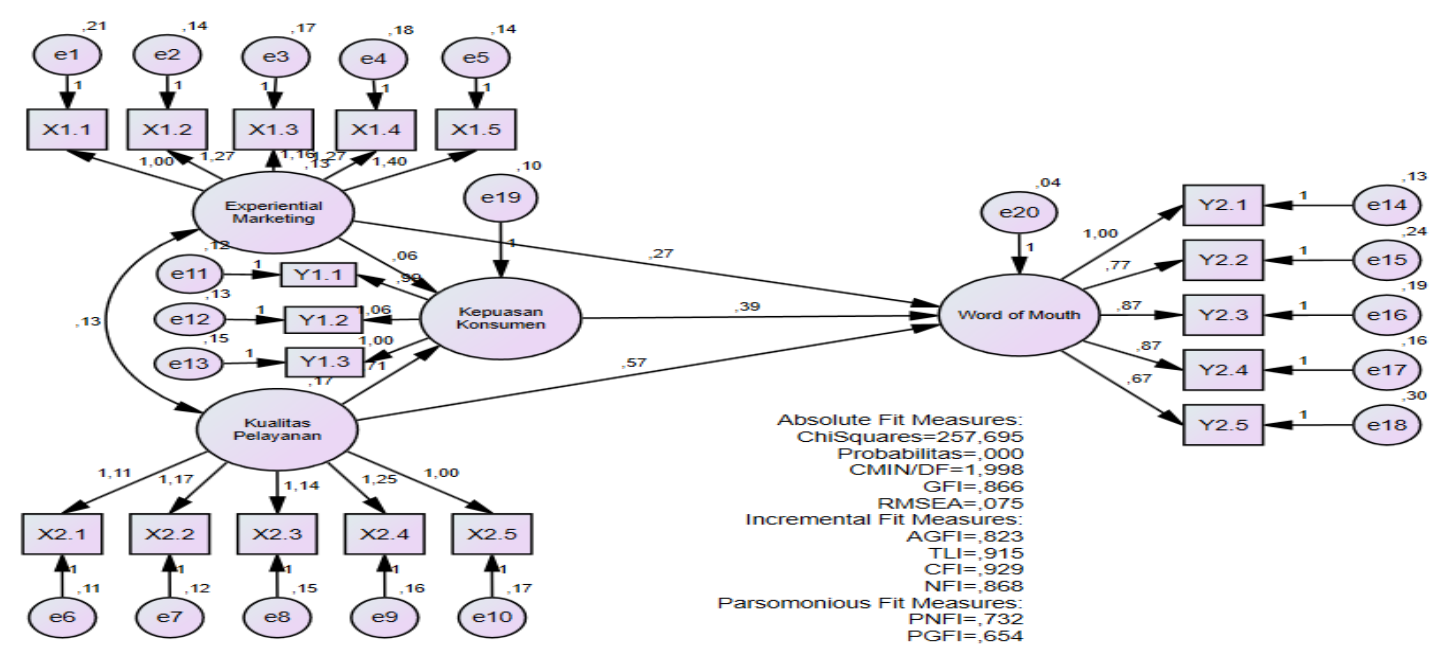

Gambar 1

Diagram Full Model Dalam SEM

Sumber: Data Primer, Diolah Tahun 2021

Sesuai gambar tersebut karena tujuannya adalah mengekspolarasi pola hubungan (interrelationship) maka terlebih dahulu dapat dianalisis hasil konfirmatori faktor eksogen yang sekaligus dapat digunakan untuk uji validitas konvergen (convergent validity) menggunakan standardized regression weights dengan loading factor diatas 0,50 seperti pada Tabel 1 dibawah ini.

Tabel 1

Hasil Uji Validitas Konvergen Pada Konstruk Eksogen Dengan Menggunakan Standardized Regression Weights

\begin{tabular}{ccccc}
\hline $\begin{array}{c}\text { Indikator Pada } \\
\text { Variabel }\end{array}$ & Estimate & $\begin{array}{c}\text { Standardized } \\
\text { Regression Weight }\end{array}$ & P-Values & Keterangan \\
\hline $\begin{array}{c}\text { X1.1 - Experiential } \\
\text { Marketing (X1) }\end{array}$ & 1,000 & 0,615 & 0,000 & Valid \\
\hline $\begin{array}{c}\text { X1.2 - Experiential } \\
\text { Marketing (X1) }\end{array}$ & 1,267 & 0,771 & 0,000 & Valid \\
\hline $\begin{array}{c}\text { X1.3 - Experiential } \\
\text { Marketing (X1) }\end{array}$ & 1,165 & 0,713 & 0,000 & Valid \\
\hline $\begin{array}{c}\text { X1.4 - Experiential } \\
\text { Marketing (X1) }\end{array}$ & 1,273 & 0,737 & 0,000 & Valid \\
\hline $\begin{array}{c}\text { X1.5 - Experiential } \\
\text { Marketing (X1) }\end{array}$ & 1,403 & 0,806 & 0,000 & Valid \\
\hline $\begin{array}{c}\text { X2.1 - Kualitas } \\
\text { Pelayanan (X2) }\end{array}$ & 1,108 & 0,807 & 0,000 & Valid \\
\hline $\begin{array}{c}\text { X2.2 - Kualitas } \\
\text { Pelayanan (X2) }\end{array}$ & 1,166 & 0,806 & 0,000 & Valid \\
\hline $\begin{array}{c}\text { X2.3 - Kualitas } \\
\text { Pelayanan (X2) }\end{array}$ & 1,142 & 0,770 & 0,000 & Valid \\
\hline
\end{tabular}




\begin{tabular}{ccccc}
\hline $\begin{array}{c}\text { Indikator Pada } \\
\text { Variabel }\end{array}$ & Estimate & $\begin{array}{c}\text { Standardized } \\
\text { Regression Weight }\end{array}$ & P-Values & Keterangan \\
\hline $\begin{array}{c}\text { X2.4 - Kualitas } \\
\text { Pelayanan (X2) }\end{array}$ & 1,250 & 0,787 & 0,000 & Valid \\
\hline $\begin{array}{c}\text { X2.5 - Kualitas } \\
\text { Pelayanan (X2) }\end{array}$ & 1,000 & 0,703 & 0,000 & Valid \\
\hline
\end{tabular}

Sumber: Data Primer, Diolah Tahun 2021

Sesuai Tabel 1 diatas diperoleh keseluruhan varaiabel manifest diatas 0,50 maka dapat dikatakan valid sedangkan untuk mengetahui kuat atau lemahanya dalam membentuk variabel (konstruk) laten dapat dilihat dari nilai critical ratio lebih besar dari 2,00 dengan tingkat signifikan kurang dari 0,05. Nilai yang terkuat membentuk variabel experiential marketing (X1) adalah indikator relate (X1.5) karena loading factor yang tecermin pada nilai standardized regression weight lebih besar daripada konstruk yang lainnya yakni sebesar 0,806 Sedangkan nilai yang terkuat membentuk variabel kualitas pelayanan (X2) adalah indikator bukti fisik (X1.1) karena loading factor yang tecermin pada nilai standardized regression weight lebih besar daripada konstruk yang lainnya yakni sebesar 0,807. Sementara itu, (Hair, Anderson, Babin, \& Black, 2010) dalam (Ghozali, 2017) menjelaskan bahwa syarat suatu variabel yang merupakan dimensi dari variabel latennya adalah jika mempunyai factor loading (estimate) harus sama dengan 0,50 atau lebih besar dari idealnya harus 0,70. Kemudian untuk hasil konfirmatori faktor endogen yang sekaligus dapat dilihat pada Tabel 2 dibawah ini.

Tabel 2

Hasil Uji Validitas Konvergen Pada Konstruk Endogen Dengan Menggunakan Standardized Regression Weights

\begin{tabular}{ccccc}
\hline Indikator Pada Variabel & Estimate & $\begin{array}{c}\text { Standardized } \\
\text { Regression Weight }\end{array}$ & P-Values & Keterangan \\
\hline Y1.1 - Kepuasan Konsumen (Y1) & 0,992 & 0,784 & 0,000 & Valid \\
\hline Y1.2 - Kepuasan Konsumen (Y1) & 1,062 & 0,794 & 0,000 & Valid \\
\hline Y1.3 - Kepuasan Konsumen (Y1) & 1,000 & 0,754 & 0,000 & Valid \\
\hline Y2.1 - Word of Mouth (Y2) & 1,000 & 0,811 & 0,000 & Valid \\
\hline Y2.2 - Word of Mouth (Y2) & 0,772 & 0,620 & 0,000 & Valid \\
\hline Y2.3 - Word of Mouth (Y2) & 0,870 & 0,708 & 0,000 & Valid \\
\hline Y2.4 - Word of Mouth (Y2) & 0,869 & 0,734 & 0,000 & Valid \\
\hline Y2.5 - Word of Mouth (Y2) & 0,675 & 0,730 & 0,000 & Valid \\
\hline
\end{tabular}

Sumber: Data Primer, Diolah Tahun 2021

Sesuai Tabel 2 diatas diperoleh keseluruhan varaiabel manifest diatas 0,50 maka dapat dikatakan valid sedangkan untuk mengetahui kuat atau lemahanya dlam membentuk variabel (konstruk) laten dapat dilihat dari nilai critical ratio lebih besar dari 2,00 dengan tingkat signifikan kurang dari 0,05. Nilai yang terkuat membentuk variabel kepuasan konsumen (Y1) adalah indikator minat 
berkunjung kembali (Y1.2) karena loading factor yang tecermin pada nilai standardized regression weight lebih besar daripada konstruk yang lainnya yakni sebesar 0,794. Sedangkan nilai yang terkuat membentuk variabel word of mouth (Y2) adalah indikator talkers (Y2.1) karena loading factor yang tecermin pada nilai standardized regression weight lebih besar daripada konstruk yang lainnya yakni sebesar 0,811.

2. Menilai Identifikasi Model Struktural

Total jumlah data kovarian dan varian adalah 171 yang mana $18(18+1) / 2$, kemudian dari hasil tersebut diperoleh jumlah parameter yang akan diestimasi adalah 42 sehingga hasilnya 171 - 42 yakni 129 (nilai degree of freedom). Dari hasil ini berarti $129>0$ sehingga model tersebut overidentified yang artinya model dapat di identifikaasikan estimasinya.

3. Evaluasi Godness of Fit

Karena model CBSEM dengan menggunakan Amos distribusinya parametrik maka terlebih dahulu harus memenuhi asumsi-asumsi dengan teknik estimasi maksimum likelihood (MLE), yaitu:

a. Uji Normalitas

Tujuan digunakannya uji normalitas data adalah untuk mengetahui apakah data yang diperoleh mempunyai distriibusi (sebaran) yang normal atau tidak. Karena CBSEM dengan menggunakan AMOS adalah distribusinya parametrik maka harus memenuhi uji normalitas data jika tidak terpenuhi maka mode penelitian tidak layak dan tidak bisa dikembangkan.

Tabel 3

Hasil Uji Normalitas Data (Assesment of Normality)

\begin{tabular}{ccccccc}
\hline Variabel min & max & skew & c.r. & kurtosis & c.r. \\
\hline $\mathrm{Y} 1.1$ & 3 & 5 & $-0,433$ & $-2,371$ & $-0,822$ & $-2,252$ \\
\hline $\mathrm{Y} 1.2$ & 3 & 5 & $-0,429$ & $-2,349$ & $-0,682$ & $-1,869$ \\
\hline $\mathrm{Y} 1.3$ & 3 & 5 & $-0,336$ & $-1,841$ & $-0,701$ & $-1,919$ \\
\hline $\mathrm{Y} 2.5$ & 3 & 5 & $-0,292$ & $-1,600$ & $-0,702$ & $-1,922$ \\
\hline $\mathrm{Y} 2.4$ & 3 & 5 & $-0,136$ & $-0,747$ & $-0,494$ & $-1,354$ \\
\hline $\mathrm{Y} 2.3$ & 3 & 5 & $-0,251$ & $-1,375$ & $-0,630$ & $-1,725$ \\
\hline $\mathrm{Y} 2.2$ & 3 & 5 & $-0,362$ & $-1,982$ & $-0,679$ & $-1,859$ \\
\hline $\mathrm{Y} 2.1$ & 3 & 5 & $-0,365$ & $-2,002$ & $-0,671$ & $-1,838$ \\
\hline $\mathrm{X} 1.5$ & 3 & 5 & $-0,229$ & $-1,253$ & $-0,629$ & $-1,723$ \\
\hline $\mathrm{X} 1.4$ & 3 & 5 & $-0,201$ & $-1,103$ & $-0,597$ & $-1,635$ \\
\hline $\mathrm{X} 1.3$ & 3 & 5 & $-0,195$ & $-1,071$ & $-0,612$ & $-1,675$ \\
\hline $\mathrm{X} 1.2$ & 3 & 5 & $-0,291$ & $-1,591$ & $-0,676$ & $-1,850$ \\
\hline $\mathrm{X} 1.1$ & 3 & 5 & $-0,42$ & $-2,303$ & $-0,706$ & $-1,933$ \\
\hline $\mathrm{X} 2.1$ & 3 & 5 & $-0,054$ & $-0,294$ & $-0,549$ & $-1,504$ \\
\hline $\mathrm{X} 2.2$ & 3 & 5 & $-0,134$ & $-0,732$ & $-0,499$ & $-1,366$ \\
\hline $\mathrm{X} 2.3$ & 3 & 5 & $-0,334$ & $-1,828$ & $-0,662$ & $-1,813$ \\
\hline $\mathrm{X} 2.4$ & 3 & 5 & $-0,275$ & $-1,505$ & $-0,728$ & $-1,993$ \\
\hline $\mathrm{X} 2.5$ & 3 & 5 & $-0,076$ & $-0,418$ & $-0,404$ & $-1,105$ \\
\hline & & & & & &
\end{tabular}




\begin{tabular}{|c|c|c|c|c|c|}
\hline Variabel min & $\max$ & skew & c.r. & kurtosis & c.r. \\
\hline \multicolumn{4}{|c|}{ Multivariate } & 7,668 & 2,167 \\
\hline
\end{tabular}

Sumber : Data Primer, Diolah Tahun 2021

Sesuai Tabel 3 diatas diperoleh hasil bahwa secara univariate nilai critical ratio skewness dari semua indikator sangat rendah yakni dibawah 2,58 dengan tingkat signifikansi 0,01 yang artinya data secara univariate terdistribusi normal. Kemudian nilai 7,668 merupakan koefisien dari multivariate kurtosis dengan nilai critical ratio 2,167 dibawah 2,58 sehingga dapat disimpulkan data terdistribusi secara normal multivariate.

b. Uji Outlier

Uji outlier digunakan untuk mengetahui apakah terdapat nilai ekstrim yang terlihat berbeda jauh dengan observasi lainnya dalam satu kondisi pengamatan terhadap jumlah sampel atau responden. Untuk melihat evaluasi terhadap multivariate outliers menggunakan tingkat $\mathrm{p}<0,001$. Jarak tersebut dievaluasi dengan menggunakan X2 pada derajat bebas sebesar jumlah variabel terukur yang digunakan dalam penelitian. Dalam penelitian ini item parameternya berjumlah 18 (delapan belas) pernyataan yang kemudian melalui program excel telah diperoleh hasil 42,312 (didapat dari chinvers $=0,001 ; 18$ ) yang artinya seluruh data atau hasil yang lebih besar dari 42,312 adalah outliers multivariate.

c. Uji Multikolinieritas dan Singularitas

Determinan dari matriks kovarians sampelnya sebesar 11,879 yang mana nilai ini jauh dari angka nol sehingga dapat disimpulkan bahwa tidak terdapat masalah multikolinieritas dan singularitas pada data yang dianalisis. Setelah memenuhi asumsi-asumsi dalam SEM dengan teknik estimasi maksimum likelihood (MLE) makada padat dievaluasi kelayakan modelnya (godness of fit) yaitu.

Tabel 4

Hasil Uji Kelayakan Model (Goodness of Fit)

\begin{tabular}{cccccc}
\hline $\begin{array}{c}\text { Uji Kelayakan } \\
\text { Model Indeks }\end{array}$ & \multicolumn{2}{c}{ Cut off Value } & Hasil Analisis & $\begin{array}{c}\text { Evaluas } \\
\text { i Model }\end{array}$ \\
\hline Chi-Square $\left(\mathrm{X}^{2}\right)$ & $\begin{array}{l}\mathrm{df}= \\
\mathrm{X}^{2} \text { Tabel }\end{array}$ & $\begin{array}{c}\text { dengan } \\
(156,508)\end{array}$ & $\alpha=0,05$ & 257,695 & Poor fit \\
\hline Sig (probability) & $\geq 0,05$ & 0,000 & Poor fit \\
\hline RMSEA & $<0,08$ & 0,075 & Good fit \\
\hline GFI & $\geq 0,90$ & 0,866 & Close fit \\
\hline CMIND/DF & $<2,00$ & 1,998 & Good fit \\
\hline AGFI & $\geq 0,90$ & 0,823 & Close fit \\
\hline TLI & $>0,90$ & 0,915 & Good fit \\
\hline CFI & $>0,90$ & 0,929 & Good fit \\
\hline NFI & $>0,90$ & 0,869 & Close fit \\
\hline
\end{tabular}




\begin{tabular}{cccc}
\hline $\begin{array}{c}\text { Uji Kelayakan } \\
\text { Model Indeks }\end{array}$ & Cut off Value & Hasil Analisis & $\begin{array}{c}\text { Evaluas } \\
\text { i Model }\end{array}$ \\
\hline PNFI & $<0,90$ & 0,732 & Good fit \\
\hline PGFI & $<1,00$ & 0,654 & Good fit \\
\hline
\end{tabular}

Sumber: Data Primer, Diolah Tahun 2021

Sesuai Tabel 4 diatas diperoleh hasil Chi-Squarehitung (X2 hitung) > Chi-Squaretabel (X2 tabel) atau 275,973 > 156,508; signifikansi 0,000 $<0,05$ yang berarti penilain fitnya lemah (poor fit); nilai RMSEA sebesar 0,075 < 0,08; nilai CMIN/DF sebesar $1,998 \leq 2,00$; nilai TLI sebesar 0,915 > 0,90; nilai CFI sebesar 0,929 > 0,90; nilai PNFI sebesar 0,732 <0,90; dan nilai PGFI sebesar $0,654<1,00$ yang berarti model good fit. Kemudian nilai GFI sebesar 0,866 < 0,90; nilai AGFI sebesar 0,823 < 0,90; dan nilai NFI sebesar 0,869<0,90 yang artinya close fit. Berdasarkan hasil pengukuran goodness of fit secara keseluruhan diatas menunjukkan bahwa model yang diusulkan dalam penelitian ini diterima yang berarti pula kecocokan model yang diprediksi dengan nilainilai pengamatan pada variabel eksogen sudah memenuhi syarat. Dari beberapa uji kelayakan model, model dikatakan layak jika paling tidak salah satu metode uji kelayakan model terpenuhi (Hair et al., 2010). Kemudian untuk pengukuran model (outer model) variabel manifestnya maka dapat menggunakan composite realibility, variance extracted, dan average variance extracted (AVE) seperti pada Tabel 5 ini.

Tabel 5

Hasil Pengukuran Model Fit (Measurment Model)

\begin{tabular}{lccc}
\hline \multicolumn{1}{c}{ Variabel } & $\begin{array}{c}\text { Composite } \\
\text { Realibility }\end{array}$ & $\begin{array}{c}\text { Variance } \\
\text { Extracted }\end{array}$ & $\begin{array}{c}\text { Average Variance } \\
\text { Extracted } \\
(\boldsymbol{A V E})\end{array}$ \\
\hline $\begin{array}{l}\text { Experiential } \\
\text { Marketing (X1) }\end{array}$ & 0,785 & 0,535 & 0,886 \\
\hline $\begin{array}{l}\text { Kualitas Pelayanan } \\
\text { (X2) }\end{array}$ & 0,795 & 0,601 & 0,892 \\
\hline $\begin{array}{l}\text { Kepuasan Konsumen } \\
\text { (Y1) }\end{array}$ & 0,700 & 0,605 & 0,837 \\
\hline Word of Mouth (Y2) & 0,773 & 0,523 & 0,885 \\
\hline
\end{tabular}

Sumber: Data Primer, Diolah Tahun 2021

Sesuai Tabel 5 diatas diperoleh hasil bahwa secara keseleuruhan semua konstruk untuk nilai composite realibility $>0,70$ dan nilai variance extracted $>$ 0,50 maka dapat disimpulkan telah memenuhi syarat relibel yang artinya nilai indikator-indikator yang digunakan sebagai observed variabel relatif mampu menjelaskan variabel laten yang dibentuknya sedangkan pengujian nilai discriminant validity yang tecermin pada nilai average variance extracted $>0,70$ yang artinya validitas masing-masing konstruk baik atau tinggi dari nilai korelasi antar konstruk laten. Setelah model pengukuran (outer model) maka dapat 
dilakukan evaluasi model struktural (inner model) dengan tolak ukur critical ratio $(\mathrm{CR}) \geq 2,00 ; \alpha=5 \%$ yang tecermin pada hasil estimasi parameter regression weight. Berikut hasil uji kausalitas (regression weight) seperti yang terlihat pada Tabel 6 .

Tabel 6

Hasil Estimasi Parameter Regression Weight

\begin{tabular}{|c|c|c|c|c|c|c|}
\hline $\begin{array}{l}\text { Hubungan Antar } \\
\text { Variabel }\end{array}$ & Estimate & S.E. & C.R. & $\begin{array}{c}\text { P- } \\
\text { Values }\end{array}$ & Label & Keterangan \\
\hline $\begin{array}{lr}\text { Experiental } & \text { Marketing } \\
\text { Terhadap } & \text { Kepuasan } \\
\text { Konsumen } & \\
\end{array}$ & 0,060 & & & 0,570 & & $\begin{array}{l}\text { H1 Ditolak - } \\
\text { Tidak } \\
\text { Signifikan } \\
\end{array}$ \\
\hline $\begin{array}{lr}\text { Kualitas } & \text { Pelay } \\
\text { Terhadap } & \text { Kepu } \\
\text { Konsumen } & \\
\end{array}$ & 0,714 & & & 0,006 & & $\begin{array}{l}\text { H2 Diterima } \\
- \text { Signifikan }\end{array}$ \\
\hline $\begin{array}{l}\text { Kepuasan Konsumen } \\
\text { Terhadap Word of Mouth }\end{array}$ & 0,395 & 0,101 & 3,913 & 0,000 & par_3 & $\begin{array}{l}\text { H3 Diterima } \\
- \text { Signifikan } \\
\end{array}$ \\
\hline $\begin{array}{l}\text { Experiential Marketing } \\
\text { Terhadap Word of Mouth }\end{array}$ & 0,268 & 0,241 & 1,109 & 0,267 & par_4 & $\begin{array}{c}\text { H4 Ditolak - } \\
\text { Tidak } \\
\text { Signifikan } \\
\end{array}$ \\
\hline $\begin{array}{l}\text { Kualitas Pelayanan } \\
\text { Terhadap Word of Mouth }\end{array}$ & 0,566 & 0,232 & 2,437 & 0,015 & par_5 & $\begin{array}{l}\text { H5 Diterima } \\
\text { - Signifikan } \\
\end{array}$ \\
\hline
\end{tabular}

Sumber: Data Primer, Diolah Tahun 2021.

Sesuai Tabel 6 diatas diperoleh hasil bahwa koefisien regresi masingmasing variabel terdapat 4 (empat) hubungan yakni experiential marketing terhadap kepuasan konsumen; dan experiential terhadap word of mouth yang mana hipotesisnya ditolak yang berarti tidak signifikan karena tidak memiliki nilai critical ratio (CR) secara keseluruhan diatas 2,00 pada taraf signifikan 5\% sedangkan kualitas pelayanan terhadap kepuasan konsumen; kepuasan konsumen terhadap word of mouth; dan kualitas pelayanan terhadap word of mouth yang mana hipotesisnya diterima yang berarti signifikan karena memiliki nilai critical ratio (CR) secara keseluruhan diatas 2,00 pada taraf signifikan 5\%.

Tabel 7

Pengaruh Langsung (Direct Effect)

\begin{tabular}{lccc}
\hline \multicolumn{1}{c}{ Variabel } & $\begin{array}{c}\text { Experiential } \\
\text { Marketing (X1) }\end{array}$ & $\begin{array}{c}\text { Kualitas Pelayanan } \\
\text { (X2) }\end{array}$ & $\begin{array}{c}\text { Kepuasan } \\
\text { Konsumen } \\
\text { (Y1) }\end{array}$ \\
\hline $\begin{array}{l}\text { Kepuasan } \\
\text { Konsumen } \\
\text { (Y1) }\end{array}$ & 0,048 & 0,659 & 0,000 \\
\hline $\begin{array}{l}\text { Word of } \\
\text { Mouth (Y2) }\end{array}$ & 0,191 & 0,460 & 0,347 \\
\hline
\end{tabular}

Sumber : Data Primer, Diolah Tahun 2020 
Sesuai Tabel 7 diatas diperoleh hasil bahwa besarnya pengaruh langsung antara variabel experiential marketing (X1) terhadap variabel kepuasan konsumen (Y1) sebesar 0,048. Pengaruh langsung antara kualitas pelayanan (X2) terhadap variabel kepuasan konsumen (Y1) sebesar 0,659. Pengaruh langsung variabel experiential marketing (X1) terhadap word of mouth (Y2) adalah sebesar 0,191. Pengaruh langsung variabel kualitas pelayanan (X2) terhadap word of mouth (Y2) adalah sebesar 0,460. Dan pengaruh langsung variabel kepuasan konsumen (Y1) tehadap word of mouth (Y2) adalah 0,347.

\section{Tabel 8}

Pengaruh Tidak Langsung (Indirect Effect)

\begin{tabular}{lcc}
\hline \multicolumn{1}{c}{ Variabel } & Experiential Marketing (X1) & $\begin{array}{c}\text { Kualitas } \\
\text { Pelayanan (X2) }\end{array}$ \\
\hline $\begin{array}{l}\text { Kepuasan } \\
\text { Konsumen (Y1) }\end{array}$ & 0,000 & 0,000 \\
\hline Word of Mouth (Y2) & 0,017 & 0,229 \\
\hline
\end{tabular}

\section{Sumber : Data Primer, Diolah Tahun 2020}

Sesuai Tabel 8 diatas mengenai pengaruh tidak langsung terlihat bahwa besarnya pengaruh tidak langsung antara variabel experiential marketing (X1) terhadap word of mouth (Y2) melalui kepuasan konsumen (Y1) sebesar 0,017 sedangkan pengaruh tidak langsung antara variabel kualitas pelayanan (X2) terhadap word of mouth (Y2) melalui kepuasan konsumen (Y1) sebesar 0,229.

Tabel 9

Pengaruh Total (Total Effect)

\begin{tabular}{lcc}
\hline \multicolumn{1}{c}{ Hubungan Antar Variabel } & $\begin{array}{c}\text { Experiential } \\
\text { Marketing } \\
\text { (X1) }\end{array}$ & $\begin{array}{c}\text { Kualitas } \\
\text { Pelayanan } \\
\text { (X2) }\end{array}$ \\
\hline $\begin{array}{l}\text { Pengaruh langsung terhadap word of } \\
\text { mouth (Y2) }\end{array}$ & 0,191 & 0,460 \\
\hline $\begin{array}{l}\text { Pengaruh tidak langsung terhadap } \\
\text { word of mouth (Y2) melalui } \\
\text { kepuasan konsumen (Y1) }\end{array}$ & 0,017 & 0,229 \\
\hline Pengaruh Total & 0,208 & 0,689 \\
\hline
\end{tabular}

Sumber : Data Primer, Diolah Tahun 2021

\section{B. Pembahasan}

Experiential marketing dengan estimasi sebesar 0,060 berpengaruh positif dan tidak signifikan terhadap kepuasan konsumen karena nilai critical ratio (CR) yakni $0,207<2,00$ dengan tingkat signifikan sebesar 0,836 $>0,05$ yang berarti H1 (hipotesis pertama) dalam penelitian ini ditolak. Hal ini bermakna bahwa semakin baik pemasaran melalui pengalaman yang dimiliki oleh konsumen pada Soto Banjar Asli Ayam Kampung Targhibul Ikhwan di Samarinda dalam menikmati hidangan 
makanan dan pelayanan yang diberikan belum mampu mendorong kepuasan yang dirasakan oleh konsumen.

Kualitas pelayanan dengan estimasi sebesar 2,760 berpengaruh positif dan signifikan terhadap kepuasan konsumen karena nilai critical ratio (CR) yakni 2,760 < 2,00 dengan tingkat signifikan sebesar 0,006 > 0,05 yang berarti H2 (hipotesis kedua) dalam penelitian ini diterima. Hal ini bermakna bahwa semakin baik kualitas pelayanan yang diberikan oleh pemilik usaha atau karyawan pada Soto Banjar Asli Ayam Kampung di Samarinda mampu mendorong peningkatan kepuasan yang dirasakan oleh konsumen.

Kepuasan konsumen dengan estimasi sebesar 0,395 berpengaruh positif dan signifikan terhadap word of mouth karena nilai critical ratio (CR) yakni 3,913> 2,00 dengan tingkat signifikan sebesar $0,000<0,05$ yang berarti H3 (hipotesis ketiga) dalam penelitian ini diterima. Hal ini bermakna bahwa semakin baik kepuasan konsumen pada Soto Banjar Asli Ayam Kampung Targhibul Ikhwan di Samarinda mampu mendorong penciptaan word of mouth yang dilakukan oleh konsumen karena telah merasakan menikmati hidangan makanan maupun pelayanannya.

Experiential marketing dengan koefisien jalur sebesar 1,109 berpengaruh positif dan tidak signifikan terhadap word of mouth karena nilai critical ratio (CR) yakni 1,109 > 2,00 dengan tingkat signifikan sebesar 0,267 < 0,05 yang berarti H4 (hipotesis keempat) dalam penelitian ini ditolak. Hal ini bermakna bahwa experiential marketing belum mampu menciptakan word of mouth melalui kepuasan yang dirasakan oleh konsumen pada Soto Banjar Asli Ayam Kampung Targhibul Ikhwan di Samarinda.

Experiential marketing berpengaruh langsung terhadap word of mouth sebesar 0,191 atau 19,1\% sedangkan pengaruh tidak langsung melalui kepuasan konsumen sebesar 0,017 atau 1,7\% dengan sumbangan efektif atau total yang dihasilkan dari 2 (dua) pola hubungan tersebut sebesar 0,208 atau 20,8\% yang diperoleh dari pengaruh langsung dan pengaruh tidak langsung. Hal ini berarti bahwa experiential marketing yang dilakukan akan menciptakan atau menimbulkan informasi positif word of mouth melalui kepuasan yang dirasakan oleh konsumen ketika menikmati dan merasakan produk yang diberikan pada Rumah Makan Soto Banjar Targhibul Ikhwan di Samarinda.

Kualitas pelayanan dengan koefisien jalur sebesar 0,566 berpengaruh positif dan signifikan terhadap word of mouth karena nilai critical ratio (CR) yakni 2,437 > 2,00 dengan tingkat signifikan sebesar 0,015 < 0,05 yang berarti H5 (hipotesis kelima) dalam penelitian ini diterima. Hasil temuan ini menunjukkan bahwa variabel kualitas pelayanan memiliki hubungan positif atau Hal ini bermakna bahwa kualitas pelayanan mampu menciptakan word of mouth melalui kepuasan yang dirasakan oleh konsumen pada Soto Banjar Asli Ayam Kampung Targhibul Ikhwan di Samarinda.

Kualitas pelayanan berpengaruh langsung terhadap word of mouth sebesar 0,460 atau 46,0\% sedangkan pengaruh tidak langsung melalui kepuasan konsumen sebesar 0,229 atau 22,9\% dengan sumbangan efektif atau total yang dihasilkan dari 2 
(dua) pola hubungan tersebut sebesar 0,689 atau 68,9\% yang diperoleh dari pengaruh langsung dan pengaruh tidak langsung. Hal ini berarti bahwa kualitas pelayanan yang baik atau positif pada Rumah Makan Soto Banjar Targhibul Ikhwan di Samarinda akan berdampak pada kepuasan konsumen yang mana jika konsumen merasa puas maka mampu menciptakan atau menimbulkan informasi atau komunikasi positif word of mouth sehinnga dapat disimpulkan bahwa kepuasan konsumen.

\section{Kesimpulan}

Experiential marketing berpengaruh positif dan tidak signifikan terhadap kepuasan konsumen. Hal ini bermakna bahwa experiential marketing belum mampu mendorong kepuasan konsumen yang mana dikarenakan sebagian besar konsumen senang dan menyukai kuliner Soto Banjar sehingga terus melakukan pembelian. Kualitas pelayanan berpengaruh positif dan signifikan terhadap kepuasan konsumen. Hal ini bermakna bahwa kualitas pelayanan yang diberikan sangat baik sehingga mampu mendorong peningkatan kepuasan yang dirasakan oleh konsumen karena kebersihan dan kenyamanannya saat menikmati produk atau kuliner serta layanannya sehingga membuat konsumen merasa harapan atau kebutuhannya sesuai. Kepuasan konsumen berpengaruh positif dan signifikan terhadap word of mouth. Hal ini bermakna bahwa kepuasan konsumen mampu mendorong penciptaan word of mouth yang dilakukan oleh konsumen karena kuliner yang enak dan aman dikomsumsi serta pelayanan yang memuaskan. Experiential marketing berpengaruh positif dan tidak signifikan terhadap word of mouth melalui kepuasan. Hal ini bermakna bahwa experiential marketing belum mampu menciptakan word of mouth melalui kepuasan yang dirasakan oleh konsumen pada Soto Banjar. Kualitas pelayanan berpengaruh positif dan signifikan terhadap word of mouth melalui kepuasan konsumen. Hal ini bermakna bahwa kualitas pelayanan mampu menciptakan word of mouth melalui kepuasan yang dirasakan oleh konsumen. 
Pengaruh Experiential Marketing dan Kualitas Pelayanan terhadap Kepuasan Konsumen dan Word of Mouth

\section{BIBLIOGRAFI}

Aristiawan, Made, S.A, Dwi Putra S. Buana, and Handry Sudiartha A. 2019. "Effect of Experiential Marketing on Word of Mouth with Satisfaction as Intervening Variable (Study at GO-JEK Customer in Mataram)." Global Journal of Management and Business Research: E Marketing 19(7).

Collier, Joel E. (2020). Applied structural equation modeling using AMOS: Basic to advanced techniques. Routledge.

Ghozali, Imam. (2017). Model persamaan struktural: Konsep dan aplikasi dengan program amos 24 edisi 7. Semarang: Universitas Diponegoro.

Hair, J. F., Anderson, R. E., Babin, B. J., \& Black, W. C. (2010). Multivariate data analysis: A global perspective (Vol. 7): Pearson Upper Saddle River. NJ.

Indriani, Rizka. (2019). Peranan Backstory dalam mempengaruhi hubungan karakter di skenario" Ujung Tangan". Universitas Multimedia Nusantara.

Kurniawan, Robert. (2016). Analisis regresi. Prenada Media.

Kusuma, Diana Fitri, \& Sugandi, Mohamad Syahriar. (2018). Strategi pemanfaatan instagram sebagai media komunikasi pemasaran digital yang dilakukan oleh Dino Donuts. Jurnal Manajemen Komunikasi, 3(1), 18-33.

Lin, Mike Tz Yauw. 2019. "Effects of Experiential Marketing on Experience Value and Customer Satisfaction in Ecotourism.” Ekoloji 28(107): 51-56.

Muhammad, Muhammad, \& Artanti, Yessy. (2016). The impact of experiential marketing on word of mouth with customer satisfaction as a intervening variable. JDM (Jurnal Dinamika Manajemen), 7(2), 182-190.

Rasyidin, Al, \& Rasyidin, Al. (2011). Demokrasi pendidikan Islam: nilai-nilai intrinsik dan instrumental. Perdana Publishing.

Wahyu, Agung Anak Gde Agung Hardi, \& Gorda, Anak Agung Ngurah Eddy Supriyadinata. (2017). Kualitas Produk, Kualitas Pelayanan Terhadap Word of Mouth Dengan Kepuasan Konsumen dan Loyalitas Pelanggan Sebagai Variabel Intervening. Jurnal Ilmiah Manajemen Dan Bisnis, 2(2), 324-336. 